\title{
Microwave Remote Sensing: Needs and Requirements Concerning Technology
}

\section{Skou, Niels}

Published in:

33rd European Microwave Conference, 2003.

Link to article, DOI:

10.1109/EUMC.2003.1263026

Publication date:

2003

Document Version

Publisher's PDF, also known as Version of record

Link back to DTU Orbit

Citation (APA):

Skou, N. (2003). Microwave Remote Sensing: Needs and Requirements Concerning Technology. In 33rd European Microwave Conference, 2003. (Vol. 2). IEEE. https://doi.org/10.1109/EUMC.2003.1263026

\section{General rights}

Copyright and moral rights for the publications made accessible in the public portal are retained by the authors and/or other copyright owners and it is a condition of accessing publications that users recognise and abide by the legal requirements associated with these rights.

- Users may download and print one copy of any publication from the public portal for the purpose of private study or research.

- You may not further distribute the material or use it for any profit-making activity or commercial gain

- You may freely distribute the URL identifying the publication in the public portal

If you believe that this document breaches copyright please contact us providing details, and we will remove access to the work immediately and investigate your claim. 


\title{
Microwave Remote Sensing: Needs and Requirements Concerning Technology
}

\author{
Niels Skou \\ Technical University of Denmark \\ Building 348, DK 2800 Lyngby, Denmark \\ Phone: +45 452538 00, e-mail: ns@oersted.du.dk
}

\begin{abstract}
Spaceborne microwave remote sensing instruments, like the imaging radiometer and the synthetic aperture radar, are over time faced with two partly conflicting requirements: performance expectations (resolution, sensitivity, coverage, a.o.) steadily increase while resource allocations (weight, power, bulk, cost) decrease. This results in needs and requirements to the development of advanced technology thus enabling future advanced systems to be viable and realistic.
\end{abstract}

\section{INTRODUCTION}

Advanced microwave components like MMICs now enable considerably smaller and lighter radiometers to be built for spaceborne systems than hitherto. Likewise, extensive but light antenna structures are underway and large aperture systems, e.g. for L-band soil moisture sensing, is becoming viable. Correlation radiometers, featuring new and fast digital correlators, find use in synthetic aperture radiometers achieving good ground resolution and imaging capability through digital processing, as well as in polarimetric radiometers measuring the full set of Stokes parameters. Finally, digital radiometers with sub-harmonic sampling have become possible due to the rapid developments within digital technology.

Also synthetic aperture radar (SAR) systems benefit from the developments mentioned above. In addition promising work on dual frequency phased array antennas has been carried out, dramatically reducing bulk and weight of the antenna system for a two frequency SAR. The next generation SAR systems requires a large bandwidth, which in combination with stringent amplitude and phase characteristics is a challenge. Interesting work on these issues can also be identified.

Thus promising technology developments are on-going and they must be and will be further enhanced in the future - thus enabling new and advanced systems to be developed as a response to ever increasing capability demands. But also being very important even for more traditional systems in these days of "smaller / better / cheaper".

\section{MicRowaVE Radrometer SySTEMS}

A typical spaceborne system, see Fig. 1, features 10 to 15 individual radiometer receivers spanning the frequency range from 6 to $90 \mathrm{GHz}$. They share a common offset paraboloid reflector antenna system. Some systems may employ fast digital correlators and/or wideband analog to digital converters. Finally a range of low frequency and digital electronics support the instrument, but these items are not under discussion here.

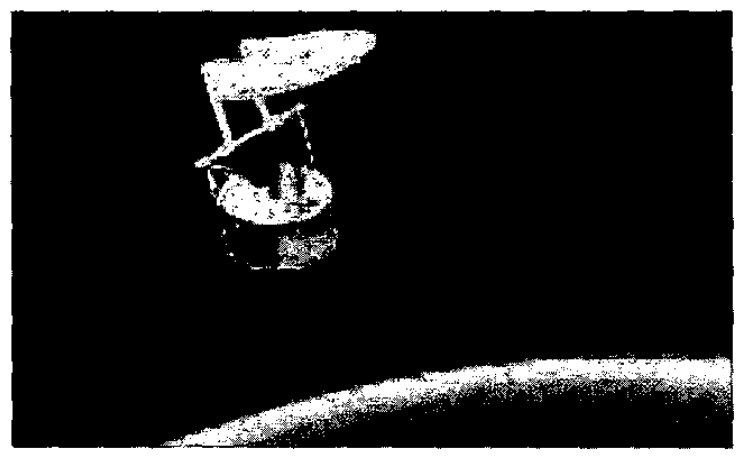

Fig. 1. Typical spaceborne radiometer system

\section{A. Microwave Receiver}

The famous SMMR launched in 1978 represents technology of the 70'es. It had 10 radiometers spanning the frequency range from $6.6 \mathrm{GHz}$ to $37 \mathrm{GHz}$. The receivers had a weight of $30 \mathrm{Kg}$ and consumed $65 \mathrm{~W}$ of power, i.e. $3 \mathrm{Kg} \& 6.5 \mathrm{~W}$ per receiver on average. The radiometers were constructed using individual waveguide components joined together using sections of waveguide. The 80 'es saw the development of the SSM/I series of multifrequency, imaging radiometers. The same technology was used, now featuring $3 \mathrm{Kg} \& 5 \mathrm{~W}$ per receiver. A dramatic change happened during the 90 'es where MMIC technology became practical even at microwave frequencies. The JASON radiometer system serves the frequencies 18.2, 23.8, and $34 \mathrm{GHz}$, and features individual receiver units about $9 \times 6 \times 3 \mathrm{~cm}$ in size, with a weight of $400 \mathrm{~g}$ and a power consumption of $2 \mathrm{~W}$. A unit includes everything from Dicke switch to A/D converter. TRW has designed and built these MMIC radiometers. Recent developments for a next generation JASON-like instrument saves additional resources by combining several receivers into one package: a 3radiometer Dicke system $(18.7,21$, and $34 \mathrm{GHz})$ is integrated into one unit about $8 \times 10 \times 2.5 \mathrm{~cm}$ with a weight of $550 \mathrm{~g}$ and consuming $4 \mathrm{~W}$. This unit is developed by Quinstar Technologies under JPL contract, see Fig. 2. Again, everything from Dicke switches to $\mathrm{A} / \mathrm{D}$ converters are included. 


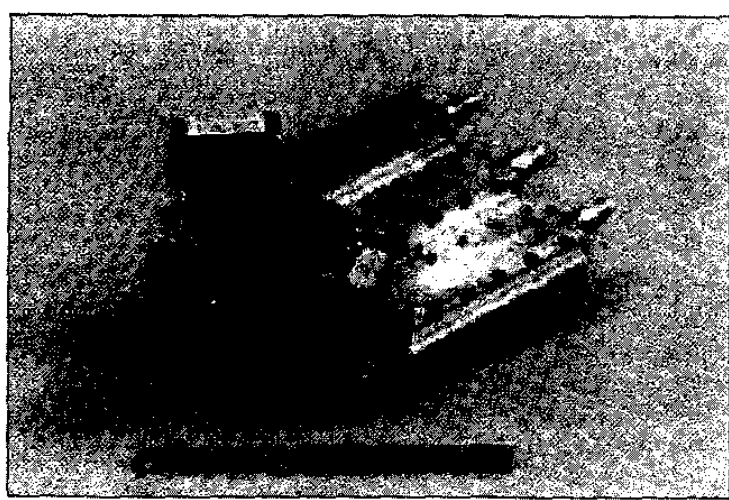

Fig. 2. 3-frequency MMIC radiometer developed by JPL / Quinstar Technologies

Thus we are presently at $180 \mathrm{~g}$ and $1.3 \mathrm{~W}$ per radiometer, and bave come a long way towards small and efficient receivers. But further developments are of course of interest, especially trying to drive down manufacturing costs.

\section{B. Antenna}

Another important resource driver is the antenna reflector. Low weight structures have been built, and it is known that a $2 \mathrm{~m}$ carbon fiber composite dish weighing $12 \mathrm{Kg}$ has been launched into space. Similarly, a $3 \mathrm{~m}$ dish for a future ocean mission has been designed with a weight of $21 \mathrm{Kg}$. It seems like a present nule-of-thumb, concerning the weight of solid, high frequency reflectors, states a weight around 3 to $4 \mathrm{Kg}$ per square meter.

For many years the need for low frequency radiometry at L-band for example has been present. However, the huge antenna structure has been an insurmountable problem! But substantial developments have taken place recently, and now there is no doubt about the feasibility (but the price tag may still be high). A $12 \mathrm{~m}$ mesh antenna, having a weight of $85 \mathrm{Kg}$ and being able to serve an L-band radiometer, has been flown in space. A $90 \mathrm{~m}$ upgrade has been designed. A communication satellite having two $19 \times 17 \mathrm{~m}$ antennas has been designed and the antennas demonstrated. A $14 \mathrm{~m}$ inflatable parabolic reflector antenna has been built and successfully deployed in space. In parallel herewith a $27 \times 36 \mathrm{~m}$ inflatable torus reflector antenna, intended for pushbroom applications, has been designed. The weight is $211 \mathrm{Kg}$. Further developments are warranted to arrive at proven, cost effective and reliable designs.

\section{Correlation Radiometers}

With a start in the 80 'es, and very much enhanced in the 90 'es, correlation radiometers have been a hot issue. A correlation radiometer is basically 2 identical radiometers that, in addition to measuring the usual brightness temperature signals presented to their inputs, also measures the correlation between these input signals, see Fig. 3. The applications of such radiometers are in two different subject areas: synthetic aperture radiometers (where a large solid antenna reflector is traded for a lighter structure with many small antenna elements; each antenna element output is cross correlated with all others, and image formation is done by digital processing), and polarimetric radiometers (where the full Stokes vector is found by measuring the vertical and horizontal fields and the complex correlation between these). This of course presents some new requirements to the radiometers, and coherent operation, like in a SAR receiver, must be ensured: phase must be preserved through the receivers, and the 2 parallel channels must exhibit similar amplitude and phase characteristics. An obvious issue is, that superheterodyne systems must use one common local oscillator.

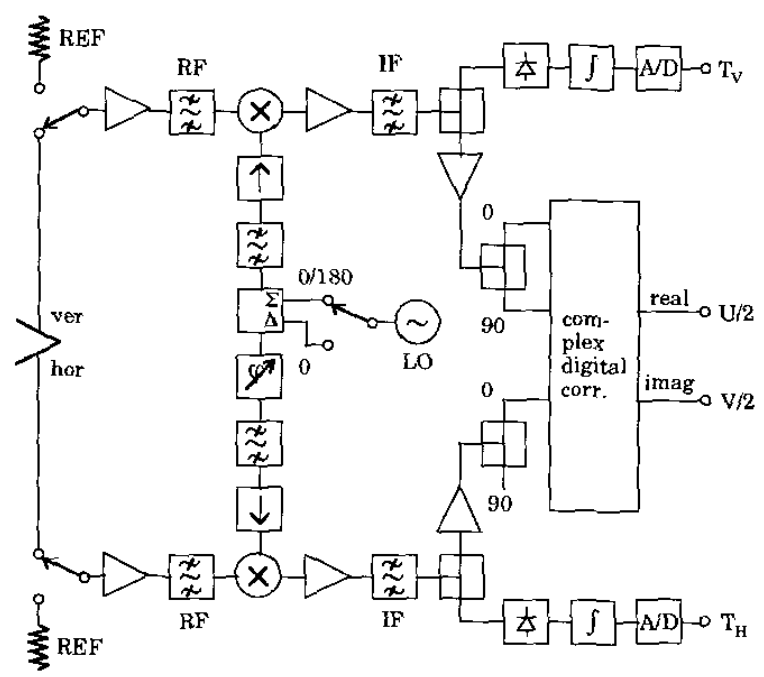

Fig. 3. Typical correlation radiometer

Analog correlators are possible and have been used, but digital systems are playing the major role nowadays. A typical microwave correlation radiometer system will feature traditional down-conversion using a mixer and a local oscillator. Typical radiometer bandwidths ranging from a few 10's of $\mathrm{MHz}$ to several hundreds of $\mathrm{MHz}$ can be handled by present day $A$ to $D$ converter systems. In some applications only one-bit conversion is needed and the process is relatively easy to handle, but also multibit applications are now handled by off-the-shelf components like for example 8 bit converters having $1.6 \mathrm{GHz}$ bandwidth. The problem thus is not so much the availability of circuits the handle the tasks, but excessive power consumption.

A synthetic aperture radiometer could typically have 73 individual receives and 2628 digital correlators. Thus the power consumption of the $73 \mathrm{~A}$ to $\mathrm{D}$ converters is certainly an issue, but even more so is the importance of developing very low power digital correlators running at clock speeds up to several hundreds of $\mathrm{MHz}$. 


\section{Digital Radiometer}

The availability of fast converters, and the fact that Nyquist states a sampling rate twice the bandwidth (and not twice the highest frequency), opens a new avenue within radiometer design: digital radiometers featuring sub-harmonic sampling. This way, L-band radiometers have been designed and built [3]. No analog downconversion takes place, the A/D converter directly samples the L-band signal around $1.4 \mathrm{GHz}$, the sampling rate being typically around $60 \mathrm{MHz}$ in order to properly sample the typically $27 \mathrm{MHz}$ band of an L-band radiometer. The requirement to the $\mathrm{A} / \mathrm{D}$ conversion unit is of course that the input band encompass the microwave frequency and that the sampling time jitter is compatible with the input frequency (and not just the sampling frequency). The salient features of such a digital radiometer are: flexibility, stability, less microwave hardware, potentially smaller and less power. Flexibility comes from the fact that provided some oversampling of the input band, the analog filters can be relaxed (simpler design, smaller, cheaper) and further filtering be carried out digitally. This could then be adaptive bearing in mind the interference problems that must be foreseen at some frequencies (like L-band). By proper design digital circuitry are inherently more stable than analog circuitry. Less microwave hardware is evident as no local oscillator and mixers are needed. Properly designed and integrated digital hardware is typically smaller and lighter than normal microwave hardware (here excluding the relatively expensive MMIC technology). So far, no power is saved: although the local oscillator is often quite power consuming, so are generally fast digital chips. But the development concerning reduced volume and power consumption is dramatic for digital hardware. Future developments having even higher analog bandwidth and lower time jitter will push the possible RF frequency upwards, potentially enabling this receiver topology throughout the microwave bands.

\section{SYNTHETIC APERTURE RADAR}

A typical spaceborne system will feature a phased array antenna with dimensions beyond 1 by $10 \mathrm{~m}$. As phased array antennas typically are one-frequency devices, multifrequency spaceborne systems have never materialized - although there are many good reasons from a data user point of view to have such systems. Airborne, multifrequency systems exist, but the antenna installation is certainly recognized as a cost driver. A typical spaceborne system employs a transmitter sub-system generating several $\mathrm{kW}$ of RF power. Hence, this subsystem is of particular interest when discussing resource demands (weight, power consumption, cost). Future SAR systems may have a bandwidth approaching $1 \mathrm{GHz}$. This presents little problems for the microwave electronics. For the antenna this is certainly challenging! Also, the IF and baseband part of the SAR system will be challenged by such very wide bandwidth - bearing in mind that stringent amplitude and phase characteristics requirements prevail.

\section{A. Antennas}

A bandwidth approaching $1 \mathrm{GHz}$ at for example $5 \mathrm{GHz}$ precludes the use of the standard and very popular square microstrip patches as antenna array elements. However, a bandwidth of $800 \mathrm{MHz}$ has been demonstrated at $5.6 \mathrm{GHz}$ for a large array using stacked patches as illustrated in Fig. 4, [4]. A driven patch excites a passive patch in front of it, and by proper design of sizes and distances, a large bandwidth is achieved. By careful design the configuration bears hope for even larger bandwidth.

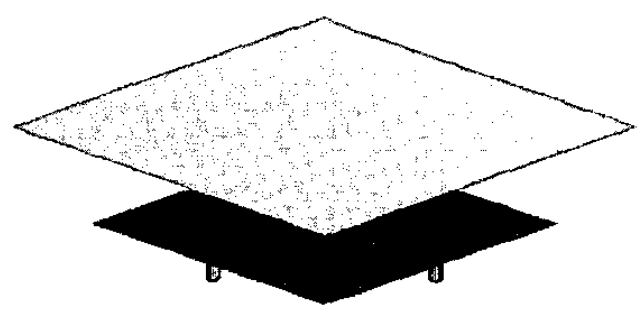

Fig. 4. C-band stacked patch

But - as already alluded to, the major antenna issue is the possibility of combining 2 antennas at different frequencies thus sharing real estate. There are certain possibilities for such a sharing, a promising one illustrated in fig. 5. Here a $5.6 \mathrm{GHz}$ array of stacked patches is combined with a $1.2 \mathrm{GHz}$ array of stacked, perforated patches. The perforations in the L-band patches allow the radiation of the $C$-band patches properly spaced over the aperture without seriously hampering the radiation of the L-band patches. Some interference between the frequencies is unavoidable, and so far 400 $\mathrm{MHz}$ at $\mathrm{C}$-band in combination with $100 \mathrm{MHz}$ at L-band has been demonstrated [4]. Further developments within this interesting research area are highly warranted.

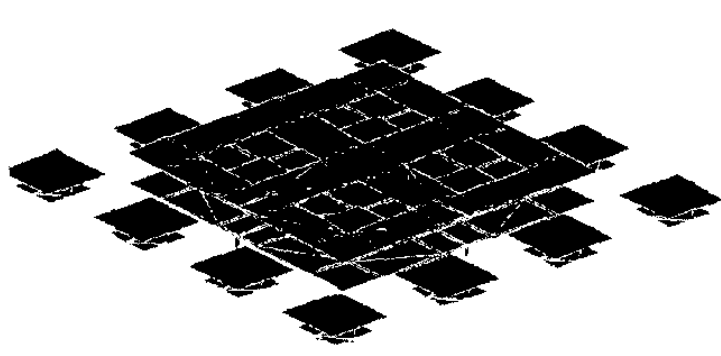

Fig. 5. L-band perforated, stacked patch with C-band stacked patches in and around it.

\section{B. Transmitters}

SAR transmitters typically takes one of two forms: a central high power transmitter (typically a TWT) feeding the phased array antenna through a feeding network, or distributed, low power transmitters (typically SSD technology) feeding a single or a small group of antenna 
elements. The paramount issue is power efficiency, and any developments here are highly appreciated, but also weight and reliability are important subjects. A recent and very promising development is the Microwave Power Module (MPM) combining the merits of TWT and SSD technology. A typical power output is $100 \mathrm{~W}$ over a very large bandwidth (more than an octave), featuring large gain and a size around 19 by 16 by $3 \mathrm{~cm}$. But also the development of small transmitters driving single antenna elements - eventually actually being integrated with the these element - is an interesting issue.

\section{IF / Baseband Components}

IF and baseband components like mixers, amplifiers, $\mathrm{U} / \mathrm{Q}$ modulators and de-modulators are to some degree available with respectable bandwidth. However, when a bandwidth beyond $1 \mathrm{GHz}$ is combined with a phase linearity requirement of better than $1^{\circ}$ not much is available, and developments are necessary. Important work is already on-going, and simple sub-systems having very large bandwidth and good phase linearity has been demonstrated offering hope for adequate systems in the near future.

\section{CONCLUSION}

In order to fulfill future requirements to advanced spaceborne microwave remote sensing systems like the imaging radiometer system and Synthetic Aperture Radar systems, certain technology developments have to take place to make actual launch technically possible and financially viable.

Of paramount importance are certain antenna developments due to the fact that the antennas are large by nature, and large structures in space are costly. Radiometer antennas first of all call for light structures, i.e. mechanical developments. SAR antennas would also gain from light structures, but the crucial item is the sharing of a common phased array aperture by several frequencies.

Especially radiometer systems with their many individual receives, but also SAR systems, benefit greatly by integrated techniques (MMIC) making small and compact systems possible.

The SAR system power and weight budget is dominated by the transmitter, and improved power efficiency is much desired as well as weight saving measures.

Especially SAR systems, but aIso to some degree correlation radiometers, depend on the availability of large bandwidth components at the same time featuring a linear phase characteristic. This is especially difficult to achieve at IF and baseband level, and important developments are needed here.

SAR systems and certain radiometer systems depend on very fast, low power digital systems, especially analog to digital converters running at several $\mathrm{GHz}$ clock speeds, and highly integrated correlators - thousands of correlators per system.

\section{REFERENCES}

[1] N. Skou, "Problems to be Addressed by Microwave Radiometer Systems in the 2l'st Century: Where Are We and Where are We Heading? Workshop Report," IEEE Geoscience and Remote Sensing Society Newsletter, pp. 17-22, March 1999.

[2] S. Madsen and N. Skou, "Problems to be Addressed by SAR Systems in the 21'st Century: Where Are We and Where are We Heading? Workshop Report," IEEE Geoscience and Remote Sensing Society Newsletter, pp. 6-13, March 1998.

[3] J. Rotbøll, S. S. Søbjarg, and N. Skou, "A novel L-band polarimetric radiometer featuring subharmonic sampling," Radio Science, vol. 38, no. 3, pp. ?-?, March 2003.

[4] J. Granholm, "Dual-Frequency and Dual-Polarization Antennas. An investigation of their suitability for highresolution airborne SAR," Ph. D. dissertation, LD 144, $\emptyset$ rsted•DTU, Technical University of Denmark, 2000. 